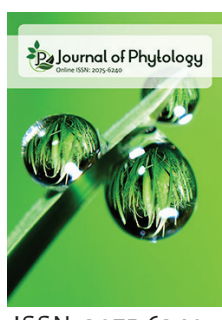

ISSN: $2075-6240$
Received: August 09, 2020 Revised: September 07, 2020 Accepted: September 12, 2020 Published: September 15, 2020

${ }^{*}$ Corresponding author:

Neetin Desai

Email: neetindesai@gmail.com

\section{Characterization of tissue specific expressed proteins and metabolites in Cenchrus polystachion (L.) Schult and their role in apomixis}

\author{
Deepti Somayajula', Sagar Barage', Neetin Desai²* \\ ${ }^{1}$ Amity Institute of Biotechnology, Amity University, Mumbai-Pune Expressway, Panvel, Mumbai, Maharashtra, India. \\ ${ }^{2} N M I M S$, Kharghar, Mumbai, Maharastra, India
}

\begin{abstract}
Agricultural production can be aggrandized by adaptation of trending technologies or processes which focus on increase in seed production. Asexual reproduction in plants or Apomixis is such a process, but its absence in major crop plants has paved an increased research towards understanding the process of apomixis. In present study an attempt was made to understand the role of differentially expressed proteins and metabolite in plant parts like leaf, stigma, immature ovary, seed, anther sac and pollen grains of Cenchrus polystachion. 563, 936, 1188, 770, 721 and 712 proteins and 6118 , 6784, 6192, 6615, 5797 and 5791 metabolites were obtained from leaf, stigma, immature ovary, seed, anther sac and pollen respectively on proteome and metabolome analysis. Some of the differentially expressed proteins and metabolites unveiled the important pathways for apomixis in Cenchrus. The top most pathways involved in apomixis are sphingolipid metabolism, glycerophospholipid metabolism, pantothenate and CoA biosynthesis, alpha linolenic acid pathway and brassinosteroid biosynthesis. The detailed analysis of the all the tissues gave an insight of the overexpression of GNDI Inhibitor (Guanosine nucleotide diphosphate dissociation inhibitor) in immature ovary. The molecular docking study further revealed that the GoLOCO motif of GNDI efficiently interacts with G alpha protein which interferes with the binding of $\mathrm{G}$ alpha with PLD alpha (Phospholipase D alpha). Thus, the overexpression of G alpha Inhibitor might exert their effect on PLD alpha leading to meiosis inactivation and formation of apomictic seed.
\end{abstract}

KEYWORDS: Apomixis, Cenchrus polystachion, Guanosine nucleotide dissociation inhibitor, Metabolomics, Phospholipase D, Proteomics

\section{INTRODUCTION}

Agriculture industry is witnessing the increase in demand with increasing population globally. To fulfil the ever-increasing demand, new methods need to be explored based on the processes involved in seed production. [1] Apomixis, occurring in few species of plants, has the ability for huge seed production resulting also in maternal clones.[2] Apomixis can be a promising technology for hybrid seed production and it can bring a revolution in agriculture field if its basis is elucidated. Cenchrus polystachion is an apomictic grass, a close relative of Pennisetum and previously available literature supports the unification of Pennisetum and Cenchrus species. [3] The studies on apomixis till date have not been able to explore its complete basis because these apomictic species are largely not agriculturally important crops and these apomicts have not been sequenced, as a reason why their genome annotations are not available.[1]
Comparative studies between sexual and apomictic species showed the differential regulation of the same allele in both types, revealing the role of nonsense and frameshift mutation for apomixis [4] like in Boechera holboellii, where deregulation of sexual pathway lead to asexual seed development with the involvement of early apomictic ovule stage genes in apomeiosis [5] [6]. In other species of a similar Boechera gunnisoniana, species, apomictic genes involved in apomeiosis were also found to be involved in embryo development pathway [7]. Few studies showed the role of mutant sexual counterpart in apomixis as for overexpressed Argonaute protein of ovary and anthers with a role in RNA silencing in mutant maize showing defects in chromatin condensation during meiosis [8] and for a homologous Serrate protein in Ferns and Arabidopsis having a role in regulation of apogamy, suggesting increase in metabolic and stress response inducing apogamy [9]. In apomictic Poa pratensis, somatic embryogenesis-like kinase (SERK) protein acts as the switch for embryo sac development and the Apostart protein controls the interaction of SERK pathway with auxin

Copyright: ๑ The authors. This article is open access and licensed under the terms of the Creative Commons Attribution License (http://creativecommons.org/licenses/by/4.0/) which permits unrestricted, use, distribution and reproduction in any medium, or format for any purpose, even commercially provided the work is properly cited. Attribution - You must give appropriate credit, provide a link to the license, and indicate if changes were made. 
pathway for apomixis [10] whereas the accumulation of zein protein was observed in early apomictic developing endosperm in Paspalum simplex [4]. In apomictic Brachiaria brizantha, GIDl gene (BbrizGIDl) expression in MMC (Megaspore mother cell) and surrounding nucellar cells and in MMC cells of its sexual counterpart indicates its role in differentiation of aposporous initial cells into aposporic embryo leading to ovule development and apomixis [11].

Large number of apomicts were also found in Gramineae [12] of which Pennisetum or Cenchrus shows similar ovule developmental pattern [13]. The key features of apomict Cenchrus ciliaris are presence of sequence characterised amplified regions (SCAR) markers, suppression of recombination, absence of correlation between apomixis and polyploidy and that they are controlled by a single locus [14] [15] indicating, that apomicts can co-exist with sexuality at different levels. In Pennisetum squamulatum apomixis is transmitted by Apomixis specific genomic region (ASGR) [16] making ASGR and BBM (Baby boom gene) the candidate genes for apomixis in Pennisetum and Cenchrus [17]. AMl (ameiotic I) and MEL2 (Meiosis arrested at leptotene) are the key genes responsible for initiation of meiosis in rice and maize whereas a homolog of AMl which is SWIl (switchl/ dyad) undergoes abnormal meiosis in Arabidopsis thaliana [18].

Even though the studies have been carried out on the genetic variations in sexual and apomictic crops but still the apomictic targets have not been completely identified and further studies needs to be undertaken to identify the role of the metabolites and proteins participating in the apomictic phenomena. Hence, the prospect of harnessing omics technology will result in identifying targets that contribute to the control of apomixis. In the present study we investigated the tissue specific expression of proteins and metabolites in six tissues of Cenchrus polystachion and subjected them to pathway analysis for identification of specific role of metabolite or protein for apomictic nature of the plant. In addition, molecular docking study was performed between GNDI inhibitor and PLD alpha respectively to investigate critical regulator of meiosis leading to apomictic seed development.

\section{MATERIALS AND METHODS}

The plant selected for the proteomic and metabolomic study was Cenchrus polystachion (accession number : 486, Department of Botany ,Savitribai Phule Pune University, India)(Domain: Eukaryota, Kingdom: Plantae, Phylum: Spermatophyta, Subphylum: Angiospermae, Class: Monocotyledonae, Order: Cyperales, Family: Poaceae, Genus: Cenchrus, Species: Cenchrus polystachion). The plant is aposporous [2] and polyploid [19] in nature. The growth and the sample collection from the plant was done in the similar way as given by Somayajula and Desai [20]. For all the analysis, the HPLC grade chemicals were used.

\section{Pollen Viability Test}

In a laminar air flow unit, anthers were split open longitudinally and pollen was released on butter paper and placed in Petri dish.
These pollens were stained by acetocaramine staining method of Rathod et al. [21].

\section{Metabolite Profiling}

Metabolites were extracted from the tissues of Cenchrus polystachion. $100 \mathrm{mg}$ each of the tissue of Cenchrus polystachion was harvested and immediately frozen in liquid nitrogen. The tissues were homogenised at $4^{\circ} \mathrm{C}$ in chilled mortar pestle and the samples were transferred in to a clean and sterile eppendorf tube for further treatment. The metabolite profiling was demonstrated by two methods for the leaf tissue namely, 1. Folch et al. method [22] 2. Weckwerth et al. [23] method and the best method was then chosen for all other tissues.

In Folch et al. [22] method, the homogenized tissue was subjected to a $1 \mathrm{ml}$ of extraction buffer with a composition of 2:1 of chloroform: methanol. The sample buffer mixture was vortexed for 4 minutes and the solution was then centrifuged at $20000 \mathrm{rpm}$ for 4 mins to remove the insoluble material. The supernatant was washed with 0.2 of volume of water. The mixture was then centrifuged at low rpm to separate the two phases. Metabolite extraction was also performed according to Weckwerth et al. [23]. The tissue was extracted with $1 \mathrm{ml}$ of extraction reagents composed of Chloroform: Methanol: Water $(\mathrm{C}: \mathrm{M}: \mathrm{W})$ in ratio of $1: 2.5: 1(\mathrm{v} / \mathrm{v} / \mathrm{v})$. The samples were shaken in batches of 10 for 5 mins at $4^{\circ} \mathrm{C}$ and subjected to centrifugation at $20000 \mathrm{rpm}$ at 4 mins. The supernatant was collected and $400 \mu \mathrm{l}$ of HPLC grade water was added and vortexed for 10 secs. The centrifugation was done with the same conditions for phase separation. The upper methanol phase contains polar metabolites and lower lipophilic phase may contains lipidic metabolites. The phases were immediately subjected for vacuum drying in Speed Vacuum Evaporator from Thermo Fischer Scientific and subjected to high throughput analysis by spectrometry.

Thus, prepared polar phases were analysed on a 1290 Infinity UHPLC System, 1260 infinity Nano HPLC with Chip cube, 6550 i Funnel Q-TOFs by Agilent system coupled to a QTOF Premier MS detector with dual AJS ESI ion source. The mass spectra were acquired by full scan MS in positive and negative ionization mode. A Cl8 column (Hypersil gold 3micron $100 \mathrm{x}$ $2.1 \mathrm{MM}$ ) was used. Water containing $0.1 \%$ Formic acid (Buffer A) and Acetonitrile containing $0.1 \%$ Formic acid (Buffer B) was used as the mobile phases for chromatographic separation. The compounds were separated by a gradient: 1 min 99\% A, 13 min linear gradient from $99 \%$ A to $65 \%$ A, 14.5 min linear gradient from $65 \%$ A to $30 \%$ A, 15.5 min linear gradient from $30 \%$ A to $1 \%$ A, hold $1 \%$ A until 17, 17.5 min linear gradient from $1 \% \mathrm{~A}$ to $99 \% \mathrm{~A}$, and requilibrate the column for $2.5 \mathrm{~min}$ [24]. The flow rate was $0.2 \mathrm{ml} / \mathrm{min}$ with the column temperature set to $40^{\circ} \mathrm{C}$.

Gas chromatography- mass spectrometry (GC GC TOF MS) analyses of apolar metabolites was carried out by LECO GC GC TOF MS. The two-dimensional output helps in resolving the peak of target analytes even when matrix interferences are present. The enhanced spectral collection rate of the 
TOF-MS detector together with the software capabilities can help in de-convolution of co-eluting compounds. Injection of samples was performed with a split/split less injector at a constant temperature of $230^{\circ} \mathrm{C}$. Injection volume was $1 \mathrm{ml}$ and was performed at a split ratio of 1:50, and all samples were measured in triplicates. Gas chromatographic separation was conducted on HP-5MS column (Primary Column: Rxi 5-MS $(30 \mathrm{~m})$ and Secondary Column: Rxi 17Sil MS (2 m)) using helium as a carrier gas at a flow rate of $1 \mathrm{ml} / \mathrm{min}$. Temperature gradient started at $70^{\circ} \mathrm{C}$ isothermal for $1 \mathrm{~min}$, followed by a heating ramp of $9^{\circ} \mathrm{C} \mathrm{min}^{-1}$ to $330^{\circ} \mathrm{C}$ held for 7 mins. Transfer line temperature was $250^{\circ} \mathrm{C}$ and ion source temperature was set to $200^{\circ} \mathrm{C}$. Mass spectra were acquired with an acquisition rate of 20 spectra $\mathrm{S}^{-1}$ at a mass range of mas-to-charge ratio 40 to 600 Thomson using a detector voltage of $1500 \mathrm{~V}$ and electron impact ionization of $70 \mathrm{eV}$.

\section{Proteome Profiling}

Protein profiling was done from the frozen tissues of the plant. The plant samples were freeze dried in liquid nitrogen and added to mixer grinder with $2 \mathrm{ml}$ of lysis buffer. Fine paste was made and paste was transferred in new pre-cooled $15 \mathrm{ml}$ tube. The mixture was then sonicated with 6-7 strokes at interval of $30 \mathrm{sec}$. The cell-lysate was centrifuged at 10,000 rpm for 10 minutes, supernatant was collected in a new pre-cooled $15 \mathrm{ml}$ tube and the pellet was discarded. This supernatant was further centrifuged at 10,000 rpm for 15 minutes, supernatant was collected in a new pre-cooled $15 \mathrm{ml}$ tube and the pellet was discarded. This supernatant was used as whole cell lysate and amount of protein in this lysate was measured using Bradford method. The protein precipitation, trypsinization and protein identification by mass spectrometry was done as per Somayajula and Desai, 2019.

A well annotated RICE database from UNIPROT/TrEMBL (release 2018_09; 1165072 entries) was employed for protein identification and a consensus run for all the tissues was done as per the workflow given by Somayajula and Desai [20].

\section{Statistical Data Analysis}

The Mass Hunter Qualitative Analysis Software (MFE) was used for statistical analysis of metabolites. The aim of this analysis was to analyse both unidentified and untargeted compounds from the data. The molecular feature extractor algorithm extracts the list of all the compounds and the list is then exported in .cef (Compound Exchange Format) format. The .cef file is subjected to MPP (Mass Profiler Professional) software (version B 2.00, Agilent) for statistical analysis. The resulting feature files for each sample were processed by ANOVA and PCA analysis utilizing the MPP software, which aligned, normalized, visualized and filtered the molecular features (MFs), for further processing.

MPP software was employed to all significant (folder change cut off 1.5) up regulated and down regulated metabolites. The potential metabolites identified were compared with the accurate mass charge ratio in some databases, including KEGG, METLIN, LIPID MAPS and PUBCHEM, to discover related pathways. $\mathrm{P}$ value $<0.05$ and folder change cut off 1.5 was considered to be criteria for statistically significant and would be selected. For proteins, the statistical analysis was done as per the method given by Somayajula and Desai 2019. The venn diagram was produced using Venny Venn 2.1.0.

\section{Pathway Analysis}

The statistically significant metabolites and proteins were subjected to pathway analysis by Metaboanalyst 3.0 and ImPaLa Version 11. Detailed analysis of the relevant pathways was performed by Metabo Analyst 3.0 which is a free, webbased tool that combines results from a powerful pathway enrichment analysis and ImPaLa (Integrated Pathway analysis tool) version 11. Metabo Analyst, directed graph, uses the highquality KEGG pathway database as its backend knowledgebase.

\section{Molecular Modelling Studies}

\section{Homology modelling}

The sequences of Guanosine Nucleotide Diphosphate Dissociation Inhibitor (GNDI) (UniProt ID: O22470), G alpha (UniProt ID: Q0DJ33) and Phospholipase D alpha (PLD alpha) (UniProt ID: Q43007) were retrieved from UniProt protein sequence database [25]. The BLAST p programme was used to search protein data bank for identification of suitable template structure. The crystal structure 1GND [26], 2XTZ [27] and 6KZ9 [28] shows 57\%, 77\% and 77\% identity with GNDI, G alpha and PLD alpha respectively. The 1GND, 2XTZ and 6KZ9 used as template structure for prediction of three-dimensional structures of GNDI, G alpha and PLD alpha respectively. The 3D structure of GNDI, G-alpha and PLD alpha was predicted using MODELLER 9.22 [29]. In this study, 50 models were generated of GNDI, G alpha and PLD alpha using MODELLER9.22. Among these 50 models, single model was selected based on DOPE (Discrete optimized protein energy) score [30]. The structural validation and characterization of GNDI, G alpha and PLD alpha was performed using PROCHECK [31] and PROSA-Web servers [32]. The best models were used further for docking studies.

\section{Protein-protein Docking}

Molecular docking has been performed of G alpha with GNDI and PLD alpha respectively using HADDOCK server [33]. For docking between $\mathrm{G}$ alpha and GNDI, the residues E49, S50, G51, K52, T54, R191, R193, T194, N195 and Q223 of G alpha selected as active residues. While residues T180-G220 of GNDI selected as active residues for docking studies. The active residues of $\mathrm{G}$ alpha and GNDI were selected on the basis of previous experimental reports. The predicted models of $\mathrm{G}$ alpha and GNDI were mapped on previous crystal structure and corresponding residues of model were selected as active for docking studies. Similarly, for G alpha and PLD alpha docking the residues H38, H40, G46, A47, G48, E49, V214, Y219, V220, 
G221, G222, E223, F337, F349, T354, T355, A356, L357, F366, I369, M370, E371, M373, R374, R375, R377 of G alpha and L553-D59l of PLD alpha selected as active. The rest of docking parameters kept to their default values. Based on HADDCOK score, the single docked conformation was selected from highest populated cluster for further analysis.

\section{RESULTS AND DISCUSSIONS}

Apomixis is a complex phenomenon of seed development without fertilization in many plant species. Understanding this phenomenon in crop plants may help to increase crop productivity in varied environmental conditions. We selected a grass species, Cenchrus polystachion a close relative of Pennisetum for tissue specific profiling of metabolites and proteins during the flowering to seed development stage. A total of $563,936,1188,770,721$ and 712 proteins and 6118 , 6784, 6192, 6615, 5797 and 5791 metabolites were obtained from leaf, stigma, immature ovary, seed, anther sac and pollen respectively. The metabolic pathways associated with apomictic seed development were studied with our over-expressed and down-regulated metabolites and proteins associated with sphingolipid metabolism, glycerophospholipid metabolism, pantothenate and $\mathrm{CoA}$ biosynthesis, alpha linolenic acid pathway and brassinosteroid biosynthesis. On reconstruction of these metabolic pathways, it's very evident that the tissue specific expressed proteins and metabolites have important role in apomictic seed development in Cenchrus polystachion.

\section{Pollen Viability Test}

The pollen viability test for Cenchrus polystachion pollen by acetocaramine staining gave viability of $14.67 \%+0.29$ comparable to $2.1 \%$ of PI 219610: Pennisetum orientale [34] and very similar to the viability obtained on different cytotypes of four Cenchrus species i.e Cenchrus biflorus, Cenchrus ciliaris, Cenchrus pennisetiformis and Cenchrus setigerus [35]. The viability was assessed based on number of pollens stained versus unstained and the pollen were confirmed as sterile pollen or non-viable in nature.

\section{Tissue Specific Profiling Of Metabolites}

The six tissues of Cenchrus polystachion were considered for metabolite profiling namely, leaf, stigma, immature ovary, seed, pollen and anther sac. The leaf was first considered for metabolic profiling using two different methods namely Weckwerth et al., method (2004) and Folch et al., method (1957) respectively. These metabolites were analysed by LC and GC platforms for identification of polar and apolar metabolites. Weckwerth et. al., method gave a total of 6118 metabolites as compared to 4356 metabolites by Folch et. al., method. Metabolite extractability and reproducibility made Weckwerth et al., method as the better method for extraction. Thus, Weckwerth et al., method was further considered for the extraction of metabolites from all other tissues. The number of metabolites identified from the plant tissues were in the order of Leaf6118, Stigma-6784, Immature overy-6192, Seed-6615, Anther sac-5797, and Pollen-5791 respectively. These metabolites comprised of a mixture of alkaloids, flavonoids, plant-based lipids, carotenoids, natural xanthophylls, steroid alkaloids, plant growth hormones and phytosterols. Similar multiomics study in rice identified 124 unique metabolites in embryo, endosperm, around 117 in seed and 72 differentially expressed metabolites with extensive post transcriptional regulation occurring during seed development [36]. LC MS profiling in tomato seedlings, cotyledons, hypocotyls and roots generated 433 metabolites with saponin like compounds in seeds, alkaloids in roots, glycosylated flavonols in cotyledons and anthocyanins in hypocotyls [37].

\section{Tissue Specific Profiling Of Proteins}

Proteomic analysis resulted in 936, 1188 and 770 proteins from stigma, immature ovary and seed respectively as compared to 563 proteins from leaf and 721 and 712 from anther sac and pollen respectively against a rice database. Proteins analysis in three biological replicates were considered. The comparative analysis among these, 279 proteins were identified as Target Proteins (Supplementary Figure. S1). Out of the identified proteins, $47.09 \%$ were involved in the metabolic process, $9.21 \%$ in transportation process, $10.49 \%$ in a response to stimuli, $7.92 \%$ in regulation of biological process and $5.74 \%$ were involved in cell organization and biogenesis. $15.76 \%$ of proteins were membrane proteins where as $10.48 \%, 5.8 \%$ and $5.37 \%$ were cytoplasm, nucleus and mitochondrial proteins. $35.02 \%$, $14.82 \%, 10.96 \%, 11.10 \%$ and $5.65 \%$ of proteins were involved in catalytic activity, nucleotide binding, protein binding, metal ion binding and structural molecular binding respectively. In Pearl millet metabolomic and proteomic studies by Ghatak et al.,2016 [38] showed tissue specific expression of proteins in root (1095), seed (1299) and young leaf (1208) respectively identifying increased levels of drought responsive proteins, heat shock proteins, molecular chaperons and storage proteins in seeds. The multiomics study by Gallan 2017 in embryo and endosperm tissues of rice identified a total of 2212 proteins of which 673 proteins were found common in both, tissues and revealed 1426 embryo specific and 113 endosperm specific proteins. Proteomic study in maize for grain development identified 4751 proteins from all the developmental stages of which 2639 were quantified and 1235 were differentially expressed proteins demonstrating a multiplicity of proteins at different stages [39].

\section{Statistical Analysis}

The identified metabolites from tissues were analysed by MPP version B 2.2 (Mass Profiler Professional software) from Agilent technologies. The raw files were loaded into Mass Hunter from Agilent and individual raw files of the triplicate samples were first converted into. cef format for compatibility with MPP. A new project was created in MPP for the analysis of samples containing a new experiment with the grouping of the triplicates into their respective parent samples. The leaf was taken as the control group and the stigma, immature ovary, seed, anther sac and pollen were taken as samples. The quality control check was performed as the first step towards data analysis. The samples were analysed and filtered on the basis of the frequency of occurrence $(100 \%$ of entities present in at least 6 
of the samples), fold change (cut off 1.5$)$ and $\mathrm{p}$ value $(\mathrm{p}<0.05)$. After filtering a total of 19296 compounds were identified. The potential metabolites were identified by using the "ID browser" to search in Metlin database and compared with the accurate mass charge ratio in some databases, KEGG, LIPID MAPS, and PUBCHEM (Supplementary Data 1, sheet 1).

For statistical significance analysis, the one-way ANOVA and a level of probability of 0.05 was used as the criterion. Multiple correction testing was performed by Benjamini-Hochberg method. 19296 metabolites were found in total out of which 3981 metabolites were found to have significant $\mathrm{P}$ value (Supplementary Table 1). The PCA analysis was performed and in the PCA scores, each point represents an individual sample. The PCA results are displayed as score plots indicating the scattering of the samples, indicating similar metabolomics compositions when clustered together and compositionally different metabolomics when dispersed. In the PCA 3D plot (Figure. la) the metabolic profile of leaf was found closer to the immature ovary and then to pollen and seed indicating the flow of metabolites from leaf to immature ovary and the changes occurring in the reproductive tissues contributed to the development of mature seed. The final metabolites after ANOVA were considered for pathway analysis.

The protein raw files were processed for a consensus workflow with the rice database and the protein abundance was identified from this analysis using proteome discoverer 2.2 for statistical analysis (Supplementary Data 1, sheet 2). The PCA analysis was done after log transforming the data (Figure. 1b). The score plot suggests that the first two principal components ( $\mathrm{PCl}$ and $\mathrm{PC} 2$ ) explained $31.9 \%$ ( $18.5 \%$ and $12.7 \%$ respectively) of the total variance of the dataset, respectively. This analysis revealed a clear variance between the male and female tissues of the plant.

In (a) each coloured point represents a sample. The first, second and third principal components are displayed on the $\mathrm{X}$, $\mathrm{Y}$ and $\mathrm{Z}$ axis respectively. These three components represent the largest fraction of the overall variability. The blue coloured ball represents the control group or called as the sink and the rest all colours represents the samples or the source. In (b) the strong variance is seen on $\mathrm{PCl}$ and $\mathrm{PC} 2$ and correlates with tissue specific proteome functionality. Plot of the statistically significant proteins of all the tissues of Cenchrus polystachion.

\section{Pathway Analysis}

Pathway analysis focuses on the analysis of a group of metabolites and proteins related to a specific metabolic pathway in biological states. The metabolic pathways with a $\mathrm{p}$ value $(<=0.05)$ in Metaboanalyst were identified and were studied for their regulation pattern (up or down regulated) (Supplementary Figure S2 and Supplementary Table 2). Using the KEGG database, the detailed pathway was generated for each of these pathways and the regulation of tissue specific metabolites and proteins were studied. The common proteins obtained from the proteome analysis of the tissues along with metabolites were then subjected to an integrated pathway analysis using ImPaLa tool (Supplementary Table 3). Pathways with more than 500 associated entries were left out in this analysis for better interpretability. For both methods, the top-ranked pathways were the Sphingolipid metabolism, Glycerophospholipd metabolism, Pantothenate and CoA biosynthesis, Inositol phosphate metabolism, alpha -linolenic acid metabolism, and Brassinosteriod metabolism (Supplementary Data 1, sheet 3).

Plant sphingolipids tend to vary in a species and tissue dependent manner and are key cellular membrane and signalling molecules involved in several cellular activities, such as cell proliferation, cell differentiation, apoptosis, and stress responses [40]. All the identified sphingolipids biosynthesis metabolites in this study were down regulated in Anther sac, immature ovary and stigma where as in pollen were upregulated. Seed had shown an up as well as down regulated trend (Figure. 2). Phytosphingosine and dihydrosphingosine, a direct precursor of phytosphingosine were both upregulated in seed by 2.03 -fold and pollen by 4.8 -fold indicating that a high auxin transportation and high response to ABA would be prevalent in these tissues [41]. Sphingosine and 3-O-Sulfogalactosylceramide were upregulated among all other metabolites in both pollen (5.2) folds and seed (1.82) folds. Sphingosine and sphingosine 1 phosphate $(\mathrm{SlP})$ regulation is interrelated and increased levels of sphingosine can bring about direct intracellular responses by increasing the cytosolic calcium concentration $(\mathrm{Ca} 2+)$ which was also reported in Pisum sativum [42]. Phytosphingosine play import role in calcium mediated stomatal closure resulting in lesser rate of photosynthesis. The elevated levels of $\mathrm{CO}_{2}$ due to decreased rate of photosynthesis can lead to male sterility which is in line with

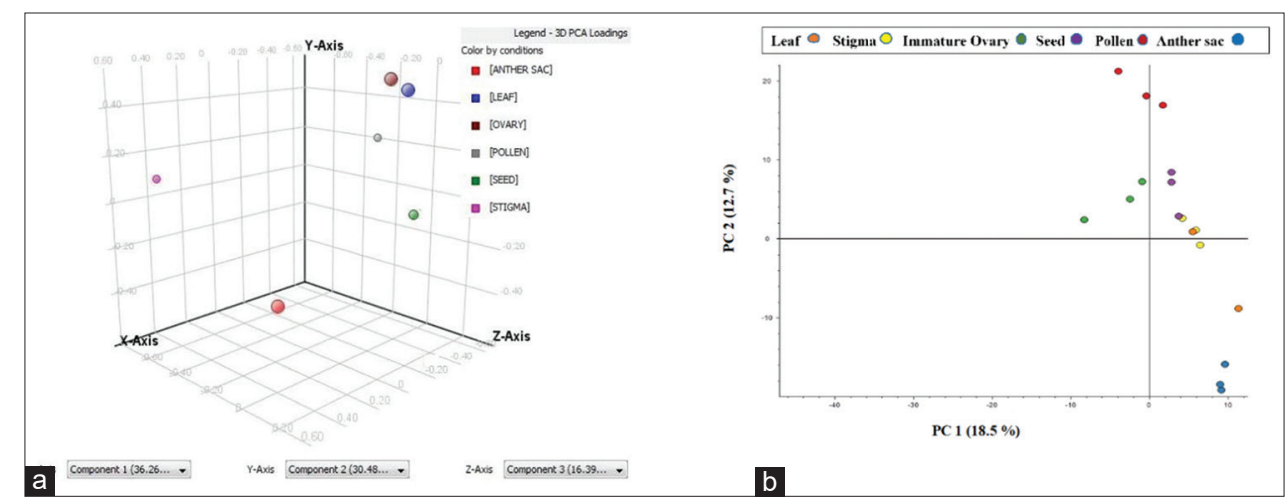

Figure 1: (a) Principal component analysis of statistically significant metabolites. 1 (b) Principal component analysis of Proteins 
studies in Oryza sativa cultivar Kirara 397, where increase CO2 levels and increase in the spikelets caused male sterility [43]. The sphingolipid pathway contributes to the accumulation of $\mathrm{CO}_{2}$ which is demonstrated in previous results of Arabidopsis thaliana and Oryza sativa, showing the correlation between seed production and $\mathrm{CO}_{2}$ accumulation [40]. S1P levels promotes stomatal closure in $\mathrm{Ca}_{2}+$ dependent and $\mathrm{ABA}$ induced manner [44].

The sphingolipid metabolism pathway in Cenchrus polystachion is upregulated in seed and pollen tissue and is responsible for the male sterile nature of the plant.

Glycerophospholipid are the main components of the cell membranes and have been widely studied for their signalling and regulatory molecules. A total of 10 metabolites and one protein from Cenchrus polystachion were mapped for Glycerophospholipid metabolic cycle, where the mapped metabolites were upregulated in pollen tissue and down regulated in the other six tissues (Figure. 3). The protein phospholipase D alpha (PLD alpha, E.C no. 3.1.4.4) was found higher in pollen followed by seed with an abundance ratio of 1.131 and 1.127 respectively and low in stigma and immature ovary with an abundance ratio of 0.0273 and 0.251 (supplementary data 2).

The level of PLD alpha was found down regulated in the female tissues of Cenchrus polystachion. PLD alpha is a main component for generation of Phosphatidic acid (PA), which has

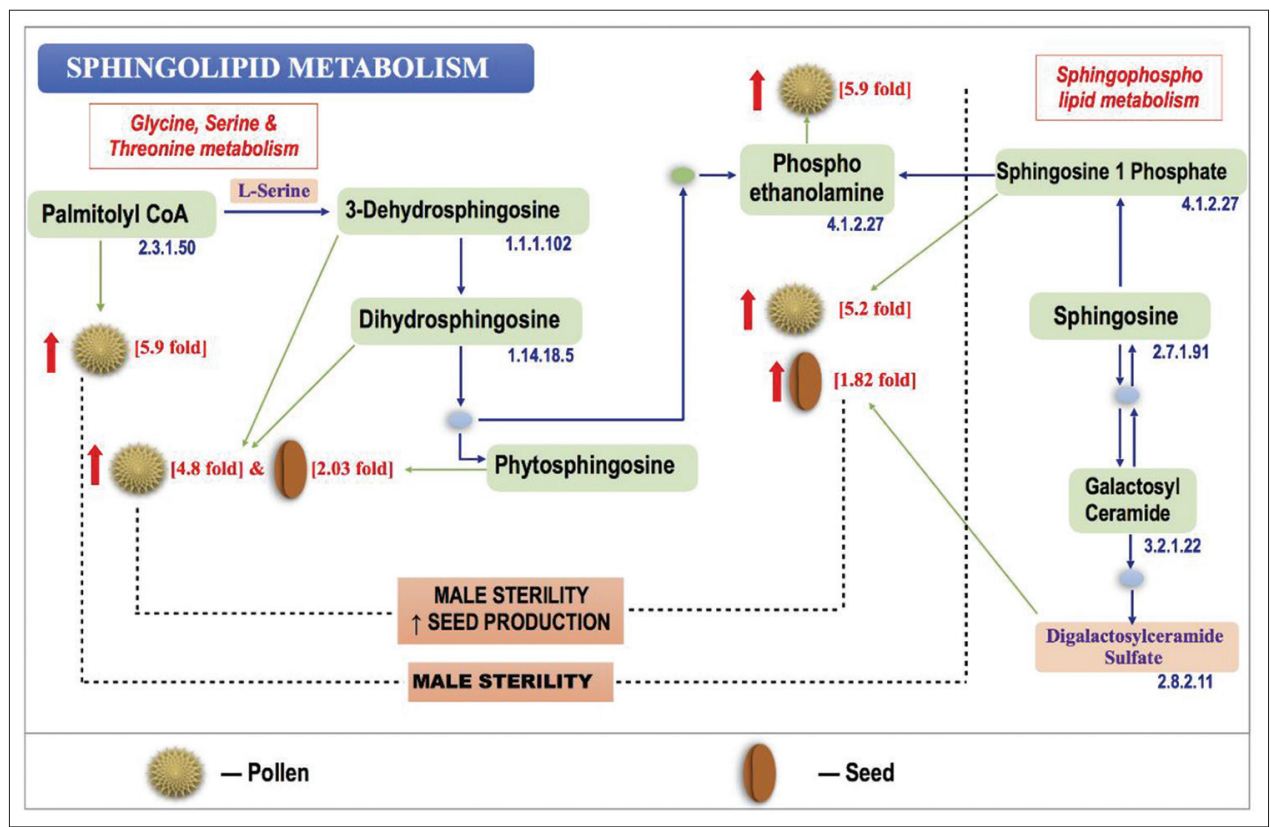

Figure 2: Sphingolipid Metabolism pathway of Cenchrus polystachion

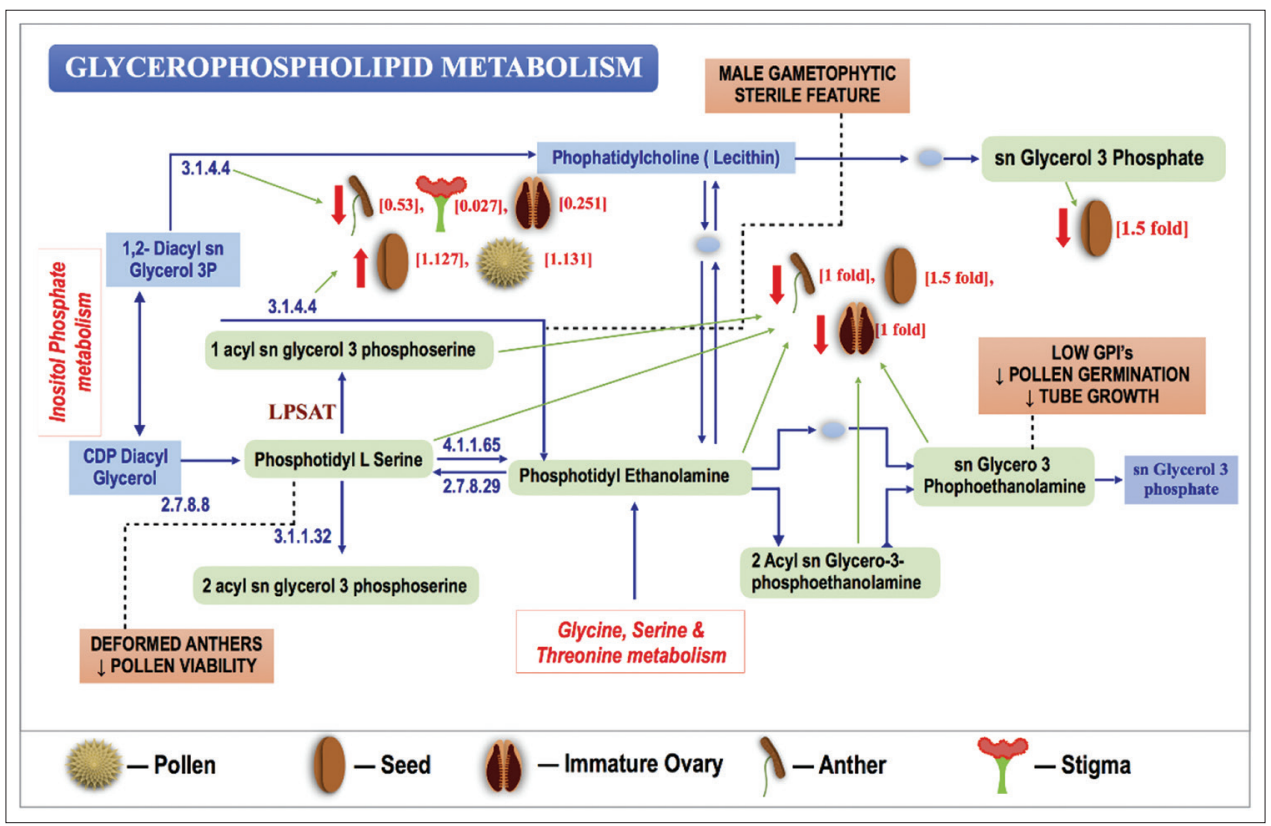

Figure 3: Glycerophospholipid Metabolism pathway of Cenchrus polystachion 
many physiological roles. PLD regulates the abscisic acid (ABA) signalling [45]. ABA inhibits stomatal opening and induces stomatal closure. The PLD alpha levels regulate PA levels and can influence the stomatal closure in the cells contributing to the male gametophytic sterile plant [46]. Phosphotidyl serine (PS) was found down regulated in anthers by l-fold which might have caused deformed and sterility in pollens is in agreement with studies on expression levels of PS and phosphotidyl serine synthase 1(PSS1) in Arabidopsis thaliana had resulted in deformed anthers and shrunken pollen with less viability [47]. The transport of PS to the nuclear membrane is important for microspore development. The deficiency in the plastidial glycolytic glyceraldehyde-3-phosphate dehydrogenase (GAPCP) was responsible for male sterility in Arabidopsis thaliana [48]. The low levels of glycerol-3-phosphoethanolamine in anthers by 1 -fold of Cenchrus polystachion may be responsible for low level of Glycosylphosphatidylinositol (GPIs) resulting in reduced pollen germination and tube growth [49]. It has been reported that phosphorylated pathway has an important function in plant metabolism and development. Plants deficient in this pathway display developmental defects in embryos, male gametophytes, and roots [50].

The Glycerophospholipid metabolism pathway in Cenchrus polystachion is downregulated and is responsible for deformed anthers and pollen leading to the male sterile nature of the plant.

The Pantothenate and CoA (Coenzyme A) pathway metabolites Phospho Pantothenate and Phosphopantotenyl L Cysteine were observed to be upregulated in pollen by 5 folds and seed by 2 folds in Cenchrus polystachion (Figure. 4). The proteins serine acetyl transferase (2.3.1.30) and aspartate aminotransferase (2.6.1.1) were upregulated in ovary and seed. The upregulation of the prospective proteins and metabolites leads to over production of the end product CoA. The enzyme phosphopantetheine adenylyl transferase (2.7.7.3) (PPAT) was over expressed as a result of increased production of CoA. Overall effect of these metabolites and proteins resulted in increased CoA. Mutation of PPAT had shown impaired plant growth and seed production by embryo lethality and overexpression showed enhanced vegetative and reproductive growth in Arabidopsis thaliana [51]. Upregulated Pantothenate and CoA biosynthesis pathway in Cenchrus polystachion may be key regulators for apomictic seed development.

The Pantothenate and CoA Biosynthesis in Cenchrus polystachion is upregulated and is responsible for the increased seed production ability of the plant even in the defective male gametophytic state of the plant.

Alpha linolenic acid metabolism involved two important metabolites (9R, 13R)-12-oxo-phytodienoic acid and (9R, 13R)la, lb-dihomo-jasmonic acid. Both these natural compounds has been reported to have a role in many developmental processes such as senescence, germination, tuber formation, fruit ripening, insect and disease resistance, drought, cold and salinity tolerance [52]. The metabolites 12-OPDA and Methyl jasmonate are upregulated in pollen by 4 folds and seed by 2 folds whereas down regulated in other organs. The protein Acetyl CoA oxidase, (E.C No.1.3.3.6) is upregulated in ovary and 3-ketoacyl-CoA thiolase 2, (E.C No. 2.3.1.16) is upregulated in all the tissues (Figure. 5). Elevated levels of these metabolites and proteins have an effect on plant development and have been reported to be associated with $\mathrm{CO}_{2}$ induced stomatal closure leading to accumulation of $\mathrm{CO}_{2}$. Elevated $\mathrm{CO}_{2}$-induced stomatal closure is known to induce ROS production in both Arabidopsis thaliana and Solanum lycopersicum [53]. The levels of Jasmonate and methyl jasmonate were down regulated in anther by 1.5 folds which shows deficient JA biosynthesis in these tissues. Earlier reports on Solanum lycopersicum mutants apparently defective in JA biosynthesis had deficient defenses and were male sterile [54]. The low levels of Jasmonic acid and its derivatives in anther

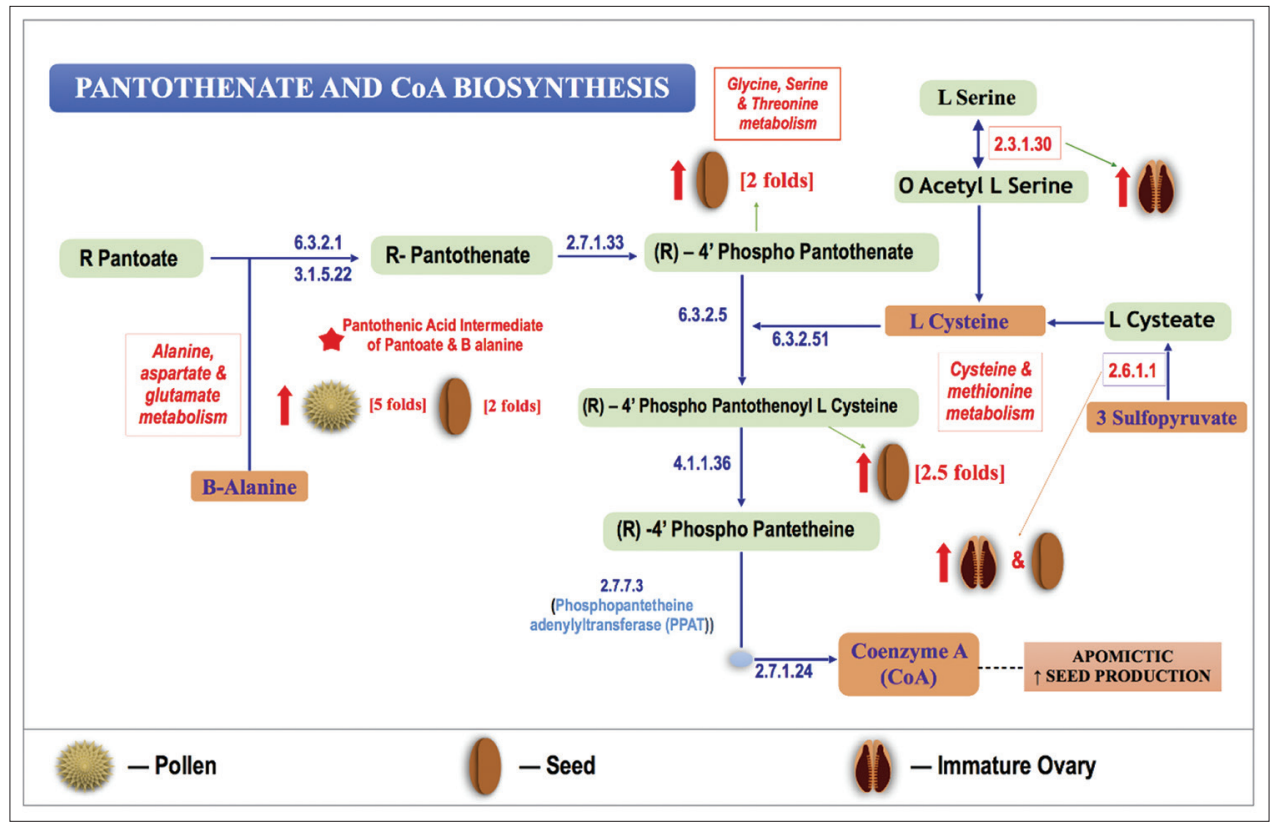

Figure 4: Pantothenate and CoA Biosynthesis pathway of Cenchrus polystachion 
indicate a deficiency in endogenous jasmonic acid (JA) leading to a delay in anther dehiscence. Jasmonic acid was reported to play role in controlling the elongation and time of anther dehiscence within the flower in Arabidopsis thaliana and Oryza sativa [55] [56] [57]. Thus, Jasmonic Acid biosynthesis has a strong role in male sterility and thus it may be one of the reasons for apomictic nature of Cenchrus polystachion.

The Alpha Linolenic Acid pathway in Cenchrus polystachion is upregulated in pollen and seed tissue but downregulated in anthers. This has led to the defective Jasmonic Acid (JA) synthesis in the plant and responsible for male sterile nature of it.
Brassinosteroids are important class of hormones and play major role in growth and development of the plant [58]. This plant had shown upregulation of the brassinosteroid metabolites in seed by 1 -fold whereas, down regulation in pollen by 2 folds, anther sac by 1 -fold and immature ovary by 1 -fold (Figure. 6). The upregulation of brassinosteroid metabolites in seed is responsible for determining the number and size of seeds in Arabidopsis thaliana [59]. The down regulation caused cell expansion defects, reduced pollen number, viability and pollen release efficiency. These defects were related with abnormal tapetum and microspore development [60]. The brassinosteroid pathway metabolites Campestenol and brassinolide downregulation

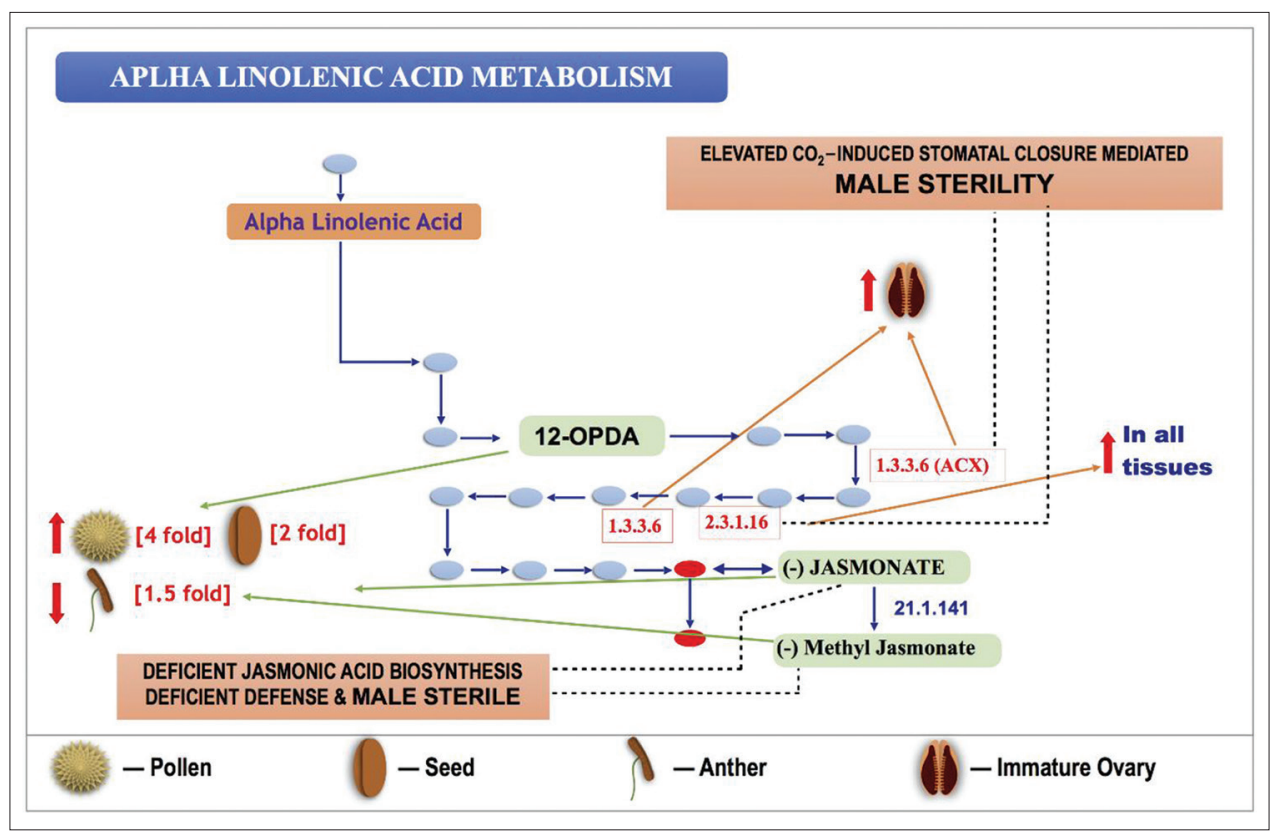

Figure 5: Alpha Linolenic Acid pathway of Cenchrus polystachion

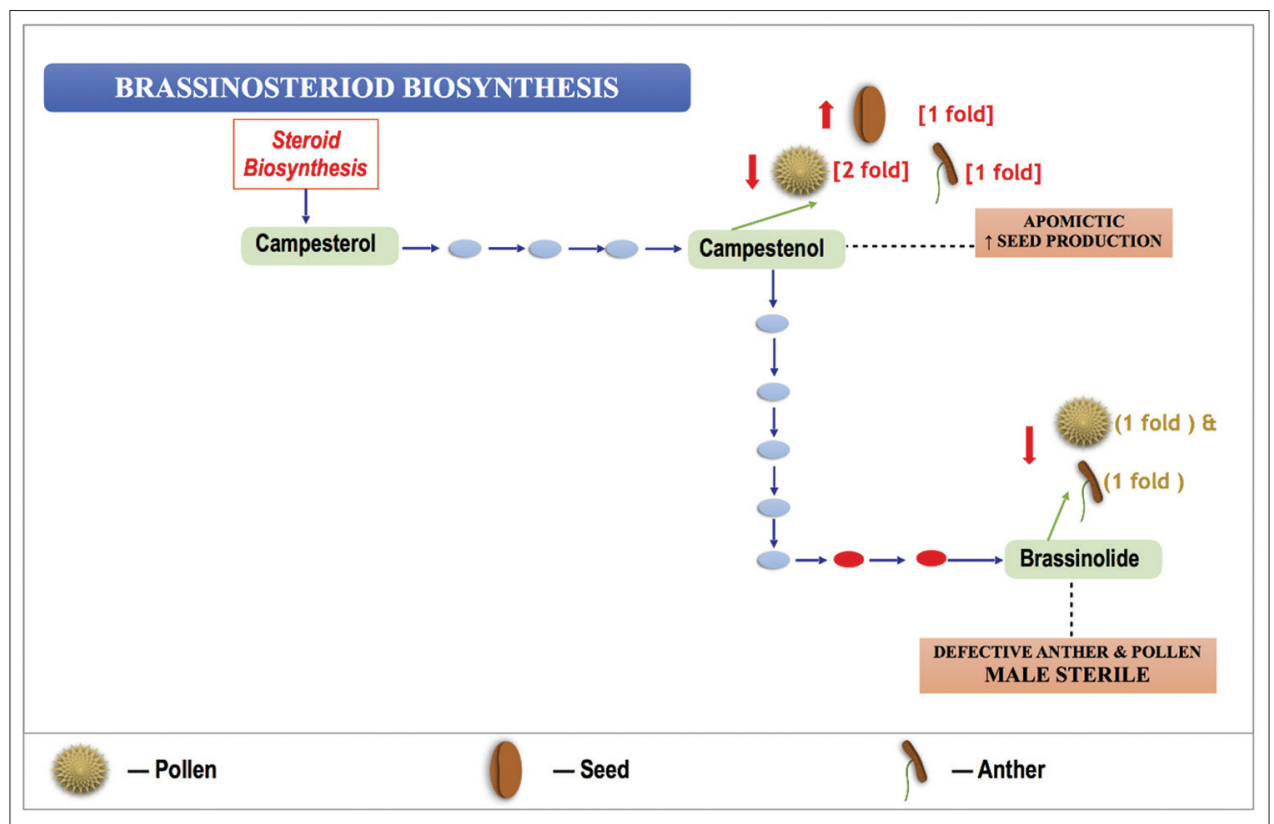

Figure 6: Brassinosteroid Biosynthesis pathway of Cenchrus polystachion 
in anther sac may be responsible for the apomictic nature of Cenchrus polystachion by their contribution towards defective anther and pollen.

The Brassinosteroid Biosynthesis in Cenchrus polystachion is upregulated in seed and downregulated in male gametophytic tissues, pollen and anther sac. This pathway has contributed for both increased seed production and male sterile nature in Cenchrus polystachion.

The high-quality KEGG metabolic pathways are the backend knowledge base to identify the most relevant pathways as listed. The results suggest that these target pathways can be a landscape in determining the pathway of apomixis in Cenchrus polystachion and could contribute to the reason behind the switch from normal reproductive pathway to an apomictic pathway.

\section{Analysis of Homology Modelling and Molecular Interactions}

\section{Homology Modelling}

The stereochemical quality of predicted homology models were analysed using PROCHECK [31] and Prosa-Web server [32]. The model of G alpha, GNDI and PLD alpha (Phospholipase $\mathrm{D}$ alpha) showed $98 \%$ residues are in allowed region as depicted in Figure. 7 (a) (b). The Prosa-web Z score of predicted models was $-6.57,-9.74$ and -10.79 respectively. The predicted homology models of G alpha, GNDI and PLD alpha predominantly consists of secondary structure elements helix, sheets and coils. Overall, the validation and characterization of model quality results show that the predicted models are in good agreement of stereochemical quality analysis and with well-validated geometry. These models were used for docking studies.
Table 1: Molecular interactions between G alpha and GNDI

\begin{tabular}{lccl} 
Residue Name & & Distance & Type of Interaction \\
\cline { 1 - 2 } G alpha & GNDI & & \\
\hline D128:0D2 & K136:HZ1 & 1.59501 & Hydrogen Bond; Electrostatic \\
R228:HH22 & D148:0D2 & 3.09246 & Hydrogen Bond; Electrostatic \\
K229:HZ1 & D148:0D1 & 2.58466 & Hydrogen Bond; Electrostatic \\
E71:0E1 & R217:NH1 & 4.57545 & Electrostatic \\
R193:NH2 & D122:0D2 & 5.18949 & Electrostatic \\
K209:NZ & D94:0D1 & 5.10849 & Electrostatic \\
Q199:0E1 & N83:HD22 & 2.82078 & Hydrogen Bond \\
R193:0 & M123:HN & 2.95848 & Hydrogen Bond \\
H232:NE2 & K209:HZ3 & 1.97068 & Hydrogen Bond \\
V197:0 & L215:HN & 2.59726 & Hydrogen Bond \\
K60:0 & R217:HE & 2.85132 & Hydrogen Bond \\
T65:0 & R217:HH12 & 2.89318 & Hydrogen Bond \\
T65:0 & R217:HH21 & 1.927 & Hydrogen Bond \\
K60:0 & R217:HH22 & 1.74792 & Hydrogen Bond \\
K57:HZ3 & R218:0 & 1.7452 & Hydrogen Bond \\
Y129:HH & M123:0 & 2.13688 & Hydrogen Bond \\
V197:HN & A212:0 & 1.80805 & Hydrogen Bond \\
Q199:HN & L215:0 & 2.44861 & Hydrogen Bond \\
R227:HN & D148:0D2 & 1.94714 & Hydrogen Bond \\
R228:HN & D148:0D2 & 1.82077 & Hydrogen Bond \\
R228:HE & D148:0D2 & 1.67739 & Hydrogen Bond \\
R228:HE & D148:0 & 2.83958 & Hydrogen Bond \\
R228:HH11 & T156:0 & 3.02167 & Hydrogen Bond \\
R228:HH12 & K155:0 & 2.96346 & Hydrogen Bond \\
R228:HH22 & D148:0 & 2.75509 & Hydrogen Bond \\
K229:HN & D148:0D1 & 1.80653 & Hydrogen Bond \\
Q199:0E1 & S214:CB & 3.33565 & Hydrogen Bond \\
E71:0E1 & F218:CA & 3.08554 & Hydrogen Bond \\
S74:CB & Q219:0E1 & 3.42079 & Hydrogen Bond \\
K229:CE & Q147:0E1 & 3.28491 & Hydrogen Bond \\
K229:CE & Q147:0 & 3.07106 & Hydrogen Bond \\
H232:CE1 & E213:0E2 & 3.45905 & Hydrogen Bond \\
I200 & R217 & 5.00162 & Hydrophobic \\
V78 & M123 & 5.2845 & Hydrophobic \\
V192 & M123 & 4.86503 & Hydrophobic \\
V198 & L215 & 4.17589 & Hydrophobic \\
Y129 & K127 & 5.42216 & Hydrophobic \\
\hline & & &
\end{tabular}

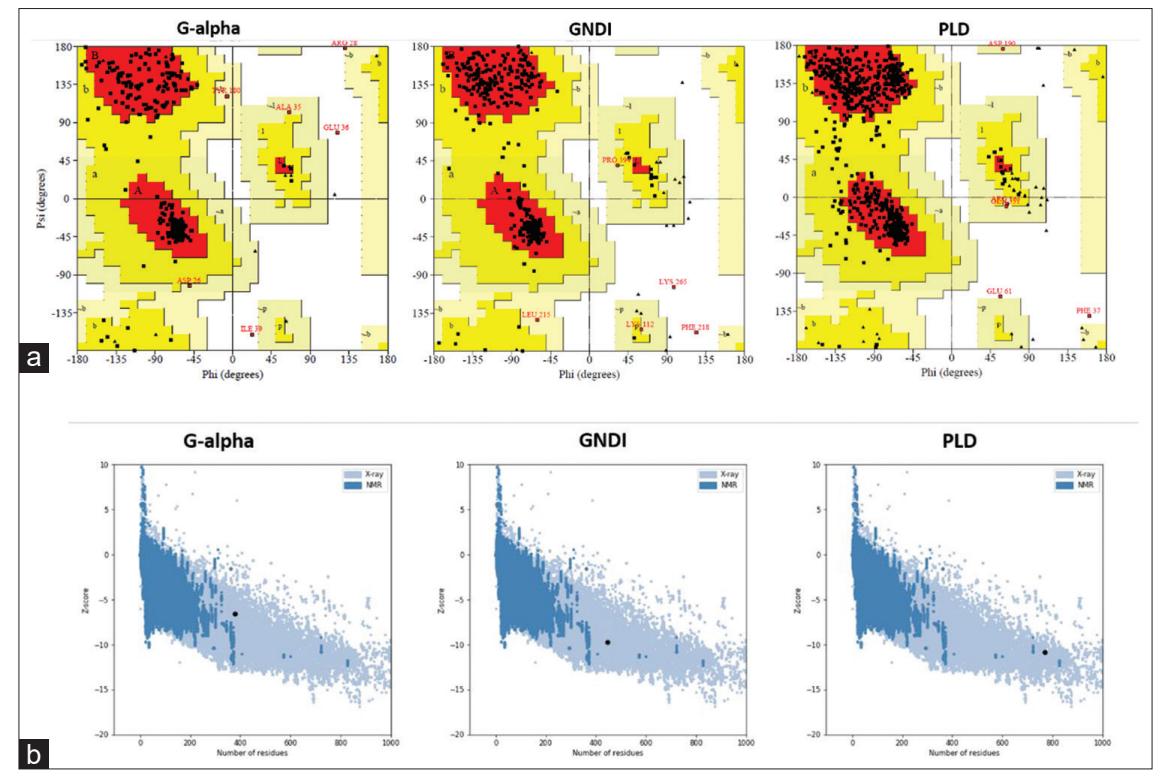

Figure 7: (a) Stereochemical quality analysis of predicted homology models: Ramachandran plot (b) Stereochemical quality analysis of predicted homology models: Prosa web Z score 
Based on our experimental study, it has been observed that there was upregulation of Guanosine nucleotide diphosphate dissociation inhibitor (GNDI) and the down regulation of PLD alpha in the apomictic ovary and stigma. The previous experimental results show that the overexpression of GNDI leads to inactivation of the $\mathrm{G}$ alpha by arresting it in GDP bound state [61] through GoLoco motif interactions [62]. It has been reported that PLD alpha is critical regulator of meiosis [45] and it is downregulated in apomictic plant of Eragrostis curvula [63].

Table 2: Molecular interactions between G alpha and PLD alpha

\begin{tabular}{|c|c|c|c|}
\hline \multicolumn{2}{|l|}{ Residue name } & \multirow[t]{2}{*}{ Distance } & \multirow[t]{2}{*}{ Type of interactions } \\
\hline G alpha & PLD alpha & & \\
\hline K330: $\mathrm{HZ3}$ & D731:0D2 & 1.66522 & Hydrogen Bond; Electrostatic \\
\hline $\mathrm{K} 364: \mathrm{HZ} 2$ & E614:0E1 & 1.65875 & Hydrogen Bond; Electrostatic \\
\hline D346:0D1 & R566:HH22 & 1.75198 & Hydrogen Bond; Electrostatic \\
\hline E333:0E1 & K744:HZl & 1.70243 & Hydrogen Bond; Electrostatic \\
\hline E326:0E2 & R747:HH21 & 1.59052 & Hydrogen Bond; Electrostatic \\
\hline K330:NZ & D730:0D2 & 3.92943 & Electrostatic \\
\hline E378:0E2 & K611:NZ & 4.0751 & Electrostatic \\
\hline E326:0E1 & K744:NZ & 4.27137 & Electrostatic \\
\hline E322:0E2 & R747:NH2 & 4.83647 & Electrostatic \\
\hline $\mathrm{K} 364: \mathrm{HZ3}$ & E614:0 & 1.92562 & Hydrogen Bond \\
\hline R374:HE & K611:0 & 2.30797 & Hydrogen Bond \\
\hline R374:HH21 & K611:0 & 1.80893 & Hydrogen Bond \\
\hline R374:HH22 & G612:0 & 2.79848 & Hydrogen Bond \\
\hline R375:HE & E565:0 & 2.20258 & Hydrogen Bond \\
\hline R375:HHI2 & Y620:0H & 2.89828 & Hydrogen Bond \\
\hline R375:HH21 & E565:0 & 1.76978 & Hydrogen Bond \\
\hline D346:0 & R566:HH21 & 2.73306 & Hydrogen Bond \\
\hline D346:0 & R566:HH22 & 2.80412 & Hydrogen Bond \\
\hline R374:0 & K611:HZ3 & 1.68204 & Hydrogen Bond \\
\hline E322:0E2 & R747:HE & 2.7105 & Hydrogen Bond \\
\hline E326:0E2 & R747:HE & 2.78321 & Hydrogen Bond \\
\hline K350 & L739 & 5.47133 & Hydrophobic \\
\hline L368 & A615 & 4.36811 & Hydrophobic \\
\hline
\end{tabular}

The PLD alpha interacts with G alpha via a DRY sequence motif analogous to GPCR as studied in Arabidopsis thaliana [64]. In line with previous reports, our quest to understand the molecular interaction of G alpha with GNDI and PLD alpha and their possible role in apomixis. Therefore, we performed molecular docking calculation between $\mathrm{G}$ alpha with GNDI and PLD alpha respectively. All docking calculations have been performed using HADDOCK server by defining active residues of protein as per previous experimental reports [33].

\section{G alpha-GNDI}

In total 103 docked conformations were obtained which was distributed in 12 clusters. The single docked conformation was selected from highest populated cluster having HADDOCK score $-80 \mathrm{Kcal} / \mathrm{mol}$. The docked complex was analysed for its molecular interactions in terms of hydrogen bonding and hydrophobic interactions at interface. The residues K60, T65, Q199, V197, R193, E71, R227, R228, K229, K57 and S74 of G alpha shows hydrogen bonding interaction with GNDI through R217, N83, L215, M123, F218, S214, D148, Q147, F218 and Q219. Furthermore, G alpha residues V78, Y129, I200 showed hydrophobic interaction with M123, K127 and R217 of GNDI residues as depicted in Table 1 and Figure. 8 (a)(b) We observed similar interaction pattern of GNDI and $\mathrm{G}$ alpha in previous studies [61] [65].

\section{G alpha - PLD alpha}

We obtained 127 docked conformation distributed in 10 clusters from HADDOCK program and selected single conformation having HADDOCK score -191 Kcal/mol from highest populated cluster. The residues contributed in interaction of $\mathrm{G}$ alpha and

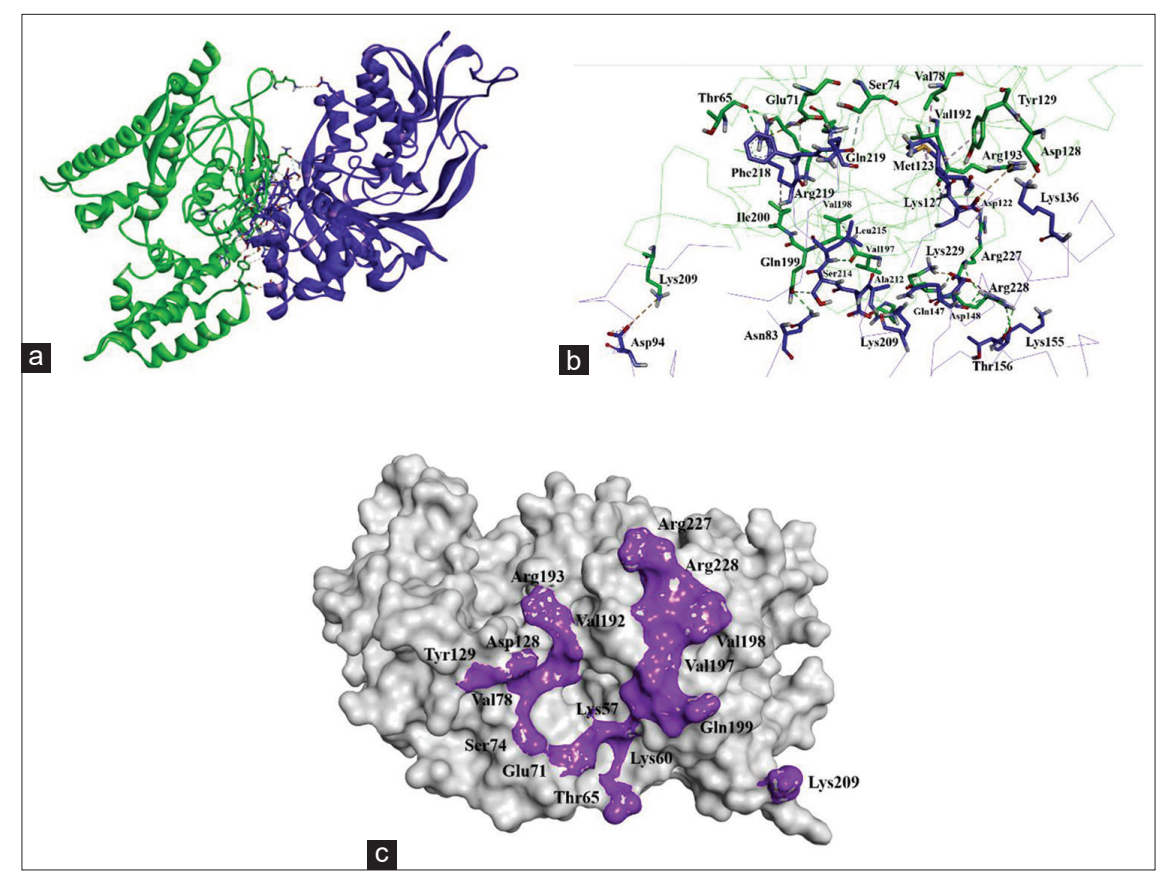

Figure 8: (a) Showing cartoon representation for binding mode of G-alpha (Green) and GNDI (blue) (b) Molecular interaction between G alpha (green) and GNDI (blue) residues represented in sticks (c) Molecular footprint of GNDI (blue) on G alpha 
PLD alpha have been analysed. It was observed that $\mathrm{G}$ alpha residues K330, K364, D346, E333, E326, E378, E322, R374, R375 and D346 showed hydrogen bonding interactions with PLD alpha residues as depicted in Table 2 and Figure. 9 (a) (b) whereas, K350 and L368 make hydrophobic interactions with L739 and A615 of PLD alpha respectively. The similar type of interactions was observed between PLD alpha and G alpha in previous studies [66].

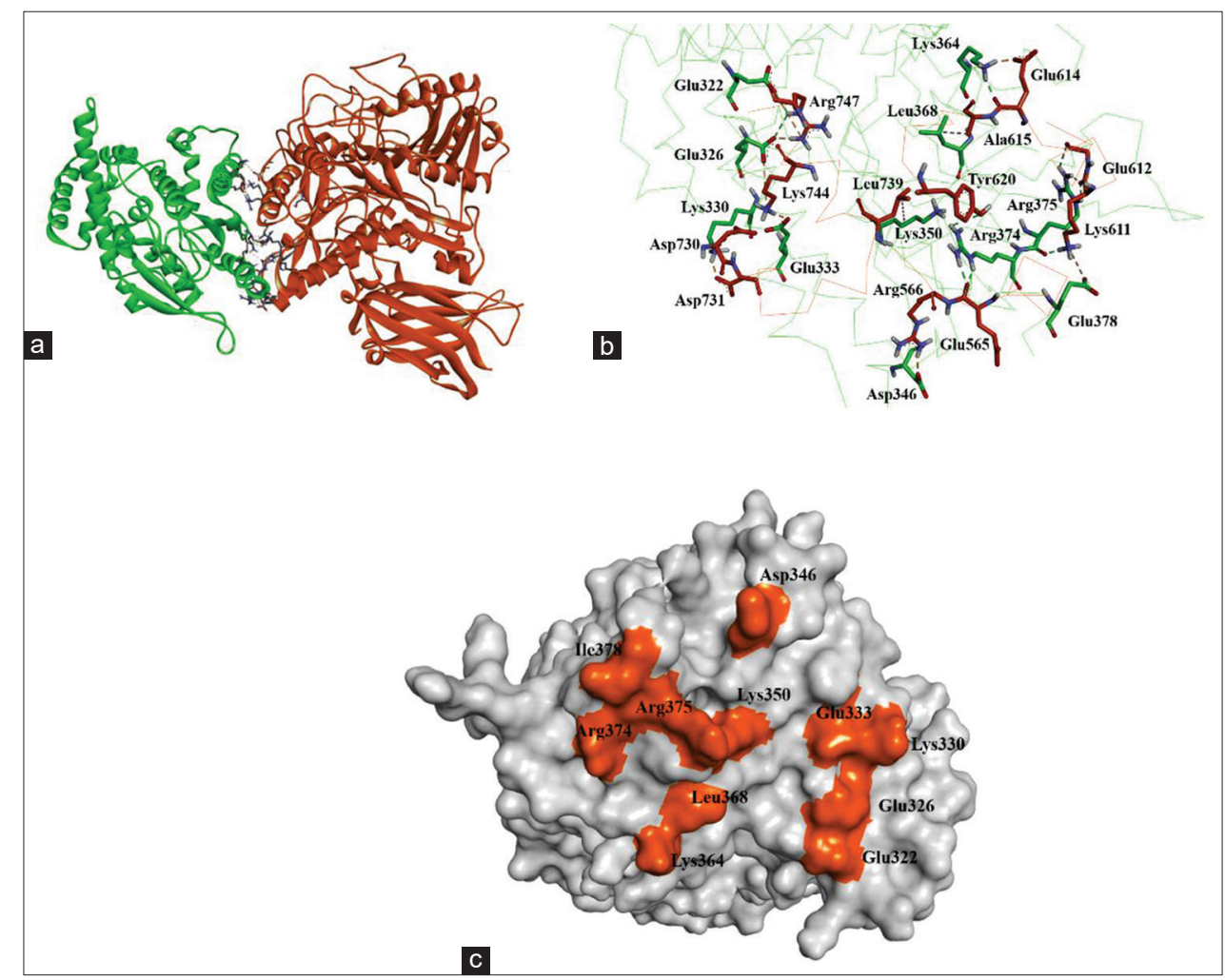

Figure 9: (a) Showing cartoon representation for binding mode of G-alpha (Green) and PLD alpha (orange) (b) Molecular interaction between G alpha (green) and PLD alpha (orange) residues represented in sticks (c) Molecular footprint of PLD alpha (orange) on G alpha

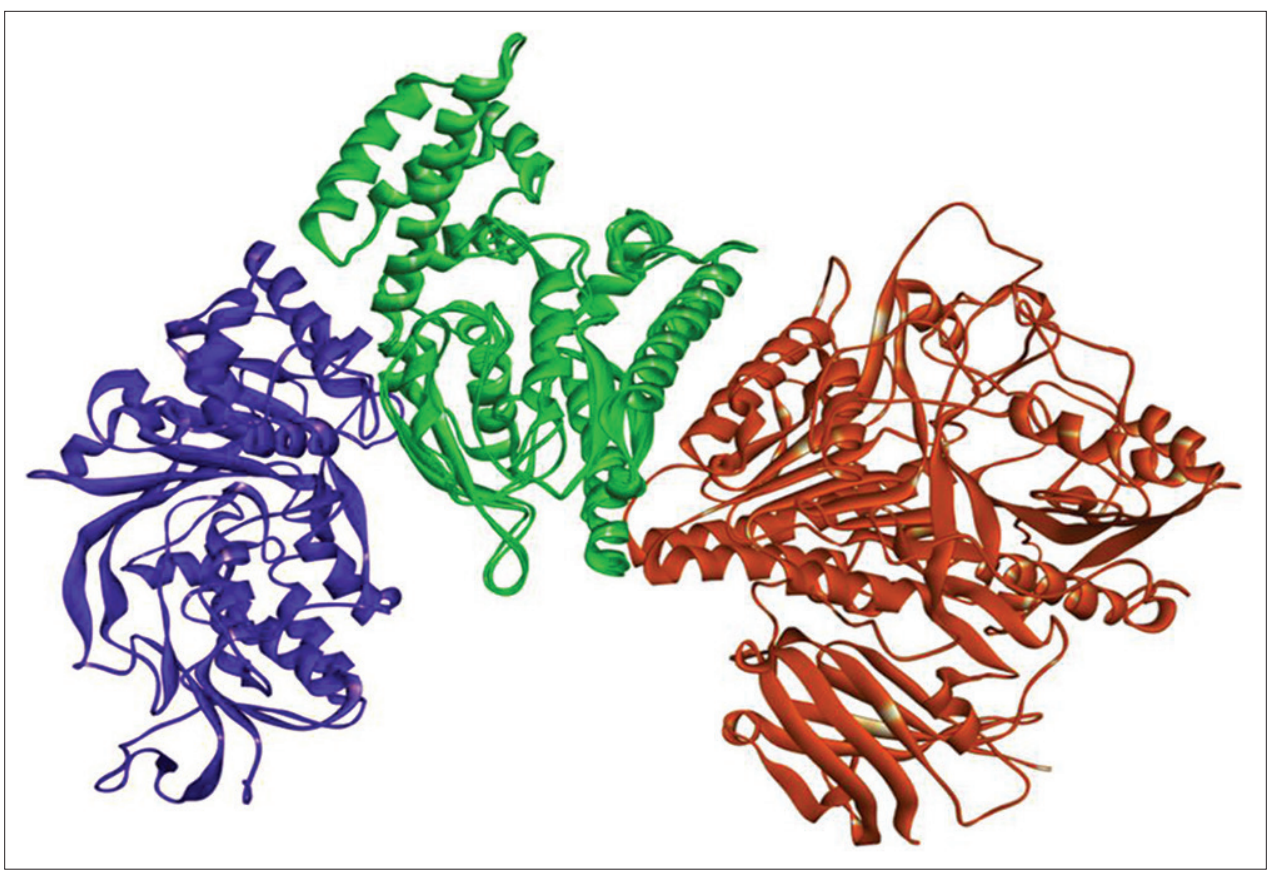

Figure 10: Showing cartoon representation for binding mode of G-alpha (Green), PLD (Orange) and GNDI (Blue) after structural superposition of docked conformations 


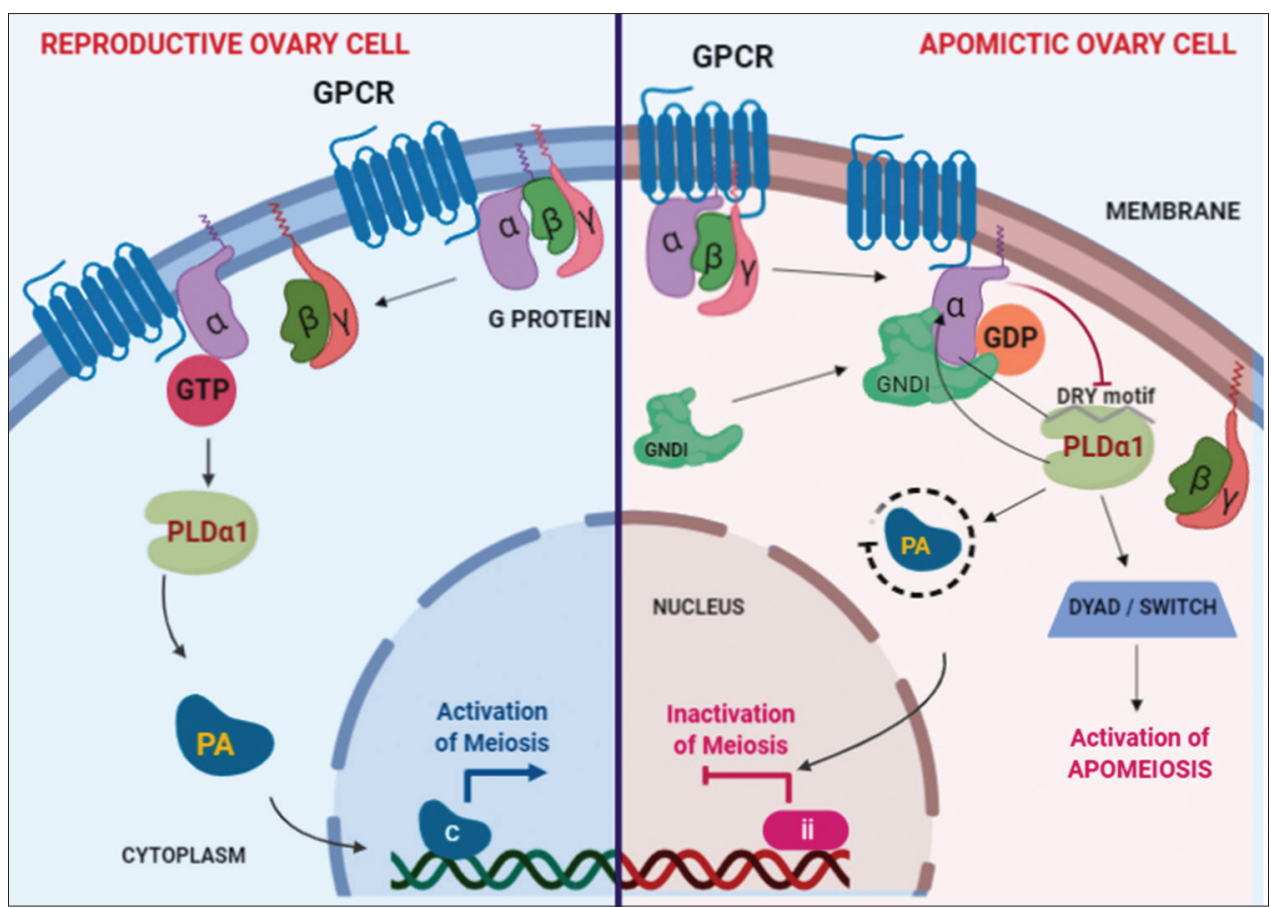

Figure 11: Speculated Apomixis pathway in Cenchrus polystachion

Overall, the docking study revealed the binding mode of GNDI and PLD alpha with $\mathrm{G}$ alpha (Figure 10) and the binding position of GNDI and PLD alpha with G alpha is opposite to each other. The GNDI and PLD alpha does not share common binding mode with $\mathrm{G}$ alpha and it was also reported in previous studies [45] [67]. Our differential expressional analysis data showed that GNDI is overexpressed in apomictic ovary. Thus, the overexpressed GNDI inhibit the activation of $\mathrm{G}$ alpha by inhibiting the dissociation of GDP state of $\mathrm{G}$ alpha which then downregulates the immediate downstream effector molecule PLD alpha, inhibiting normal meiotic process and initiating apomeiosis (Figure 11). We thus speculate on base of our docking calculations that the GNDI interaction with $\mathrm{G}$ alpha triggers apomeiosis and apomixis.

\section{CONCLUDING REMARKS}

Apomixis is a process for the production of seeds through maternal genotype forming maternal clones even when the plant skips three important steps of fertilization. Though lot of work has been done to elucidate the genes responsible for apomixis, but it warrants further studies on tissue specific expression of proteins and metabolites. In the present investigation for the first time we studied differential tissue specific expression of proteins and metabolites in Cenchrus polystachion. On the basis of data obtained and expression levels, the role of metabolites and proteins in various pathway were identified. The results are suggestive of the role of proteins and metabolites at different developmental stages is very crucial to understand the mechanism of apomixis. This study will further lead to the identification of key targets for induction of apomixis. Molecular docking studies revealed that GNDI and PLD alpha occupied opposite binding space of $\mathrm{G}$ alpha. However, we observed that bound conformation of GNDI triggers inactivation of $\mathrm{G}$ alpha leads to apomeoisis in plant.

\section{ACKNOWLEDGEMENT}

This research did not receive any specific grant from funding agencies in the public, commercial, or not-for-profit sectors.

\section{AUTHOR CONTRIBUTIONS}

The authors have contributed substantially in all of the following areas: DS, SB and ND - Conceptualization, Data Curation, Methodology, Investigations, Formal analysis, Resources, Softwares, Validation, Visualization, Drafting, Reviewing and Editing, Final approval of the version to be submitted.

\section{COMPETING INTERESTS}

The authors declare no competing interests.

\section{REFERENCES}

1. Barcaccia G, Albertini E. Apomixis in plant reproduction: a novel perspective on an old dilemma. Plant Reproduction.2013; 26(3):159-79.

2. Akiyama Y., Goel S., Conner J.A. et al. Evolution of the apomixis transmitting chromosome in Pennisetum. BMC Evolution Biology. 2011; 11: 289.

3. Chemisquy AM, Giussani LM, Scataglini MA, Kellogg EA and Morrone O. Phylogenetic studies favour the unification of Pennisetum, Cenchrus and Odontelytrum (Poaceae): a combined nuclear, plastid and morphological analysis, and nomenclatural combinations in Cenchrus. Annals of Botany. 2010; 106(1): 107-130.

4. Polegri L, Calderini O, Arcioni S and Pupilli F. Specific expression of apomixis-linked alleles revealed by comparative transcriptomic analysis of sexual and apomictic Paspalum simplex Morong flowers. Journal of Experimental Botany. 2010; Vol. 61: No. 6:1869-1883.

5. Sharbel TF, Voigt ML, Corral JM et al. Molecular signatures of apomictic and sexual ovules in the Boechera holboellii complex. The 
Plant Journal. 2009: 58:870-882

6. Sharbel TF, Voigt ML, Corral JM et al. Apomictic and Sexual Ovules of Boechera Display Heterochronic Global Gene Expression Patterns. The Plant Cell. 2010; Vol. 22: 655-671.

7. Schmidt A, Schmid MW, Klostermeier UC, Qi W, Guthorl D, Sailer C, Waller M, Rosenstiel P, Grossniklaus U. Apomictic and Sexual Germline Development Differ with Respect to Cell Cycle, Transcriptional, Hormonal and Epigenetic Regulation. PLOS Genetics. 2014; Volume 10 :Issue 7:e1004476.https://doi.org/10.1371/journal. pgen. 1004476

8. Eckardt NA.A Role for ARGONAUTE in Apomixis. The Plant Cell.2011; Vol. 23: 430.

9. Grossmann J, Fernández H, Chaubey PM, Valdés AE, Gagliardini V, Cañal MJ, Russo G, Grossniklaus U. Proteogenomic Analysis Greatly Expands the Identification of Proteins Related to Reproduction in the Apogamous Fern Dryopteris affinis ssp. Affinis. Frontiers in plant science. 2017; Volume 8: Article 336.

10. Albertini E, Marconi G, Reale L, Barcaccia G, Porceddu A, Ferranti F and Falcinelli M. SERK and APOSTART. Candidate Genes for Apomixis in Poa pratensis. Plant Physiology. 2005; Vol. 138:2185-2199

11. Ferreira LG, de Alencar Dusi DM, Irsigler AST, Gomes ACMM, Mendes MA, Colombo L, de Campos Carneiro VT. GID1 expression is associated with ovule development of sexual and apomictic plants. Plant Cell Reproduction. 2018;37(2):293-306.

12. Guohua M, Xuelin H, Qiusheng X and Bunn E. Multiporate Pollen and Apomixis In Panicoideae. Pakistan Journal of Botany.2009; 41(5): 2073-2082.

13. Ozias-Akins P, Akiyama Y, Hanna WW. Molecular characterization of the genomic region linked with apomixis in Pennisetum/Cenchrus. Functional \& Integrative Genomics. 2003; vol 3: 94-104.

14. Kumar S and Saxena S. Sequence Characterized Amplified Regions Linked with Apomictic Mode of Reproduction in Four different apomictic Cenchrus Species. Molecular Plant Breeding. 2016; Vol.7: No.8: 1-14.

15. Akiyama Y, Conner JA, Goel S, Morishige DT, Mullet JE, Hanna WW and Akins PO. High-Resolution Physical Mapping in Pennisetum squamulatum Reveals Extensive Chromosomal Heteromorphism of the Genomic Region Associated with Apomixis. Plant Physiology. 2004; Vol 134(4):1733-1741.

16. Huo H, Conner JA, Ozias-Akins P. Genetic mapping of the aposporyspecific genomic region in Pennisetum squamulatum using retrotransposon-based molecular markers. Theoretical and Applied Genetics. 2009; Volume 119: Issue 2: 199-212.

17. Hand ML and Koltunow AMG. The Genetic Control of Apomixis: Asexual Seed Formation. Genetics. 2014; Vol. 197:441-450. https:// doi.org/10.1534/genetics.114.163105

18. Wang CJR and Tseng CC. Recent advances in understanding of meiosis initiation and the apomictic pathway in plants. Frontiers in plant Science. 2014; Volume 5: Article 497.

19. Schmelzer, G., Renno, J. Genetic variation in the agamic species complex of Pennisetum section Brevivalvula (Poaceae) from West Africa: ploidy levels and isozyme polymorphism. Euphytica. 1997; 96, 23-29.

20. Somayajula D and Desai N. Optimization of protein extraction and proteomic studies in Cenchrus polystachion (L.) Schult. Heliyon. 2019; 5(12): e02968.

21. Rathod V, Behera TK, Munshi AD, Kumar D, Jat GS, Boopala Krishnan $\mathrm{G}$ and Sharma N. Pollen viability and in vitro pollen germination studies in Momordica species and their intra and interspecific hybrids. International Journal of Chemical Studies. 2018; 6(6): 32-40.

22. Ora OP and Anekwe G. E. Lipid composition of medicinal plants: Portulaca oleracea and Ficus thonningi. African Journal of Food Science. 2013; Vol. 7(5): 76-79.

23. Weckwerth W, Wenzel K, Fiehn O. Process for the integrated extraction, identification and quantification of metabolites, proteins and RNA to reveal their co-regulation in biochemical networks. Proteomics.2004; 4(1):78-83.

24. Salem MA, Jüppner J, Bajdzienko K and Giavalisco P. Protocol: a fast, comprehensive and reproducible one-step extraction method for the rapid preparation of polar and semi-polar metabolites, lipids, proteins, starch and cell wall polymers from a single sample. Plant Methods. 2016; Vol 12:45.

25. The UniProt Consortium. UniProt: a hub for protein information. Nucleic Acids Research. 2015; 43:D 204-D212.
26. SchalkI.,Zeng K., Wu S.K., Stura E.A., Matteson, J., Huang, M., Tandon, A., Wilson, I.A., Balch W.E.Structure and mutational analysis of Rab GDPdissociation inhibitor. Nature. 1996; 381: 42-48.

27. Jones J.C, Duffy J.W, Machius M, Temple B.R.S Dohlman H.G., Jones A.M. The Crystal Structure of a Self-Activating G Protein Alpha Subunit Reveals its Distinct Mechanism of Signallnitiation. Science Signalling. 2011;4(159):RA8.

28. Li J, Yu F, Guo H, Xiong R, Zhang W, He F, Zhang M \& Zhang P.Crystal structure of plant PLD alpha 1 reveals catalytic and regulatory mechanisms of eukaryotic phospholipase D. Cell Research. 2020; 30: 61-69.

29. Sali A, Blundell TL. Comparative protein modelling by satisfaction of spatial restraints. Journal of Molecular Biology. 1993;234(3):779-815.

30. Shen MY, Sali A. Statistical potential for assessment and prediction of protein structures. Protein Science. 2006; 15(11):2507-2524.

31. Laskowski RA, MacArthur MW, Moss DS, Thornton JM. PROCHECK-a program to check the stereochemical quality of protein structures. Journal of Applied Crystallography. 1993; 26:283-291.

32. Wiederstein M, Sippl MJ. ProSA-web: interactive web service for the recognition of errors in three-dimensional structures of proteins. Nucleic Acids Research. 2007: 35:407-441.

33. Van Zundert G C P, Rodrigues J P G L M, Trellet $M$ et al. The HADDOCK2.2 webserver: User-friendly integrative modeling of biomolecular complexes. Journal of Molecular Biology. 2016; 428:720-725

34. Dowling CD, Byron L. Burson BL and Jessup RW. Impediments to Hybridization between Napiergrass and different Pennisetum Species. Crop Science.2017; 57: 2043-2050.

35. Dhaliwal A, Dhaliwal RS,Kaur N and Gupta NC.Cytomorphological Study in Genus Cenchrus L.: An Important Medicinal Plant from North India (Family: Poaceae). Cytologia. 2018;83(1): 45-52.

36. Galland M, He D, Lounifi I, Arc E, Clément $G$ et al. An Integrated "Multi-Omics" Comparison of Embryo and Endosperm TissueSpecific Features and Their Impact on Rice Seed Quality. Frontiers in Plant Science.2017; vol8: article 1984

37. Roldan M.V.G, Engel B, de Vos, R.C.H. et al.Metabolomics reveals organ-specific metabolic rearrangements during early tomato seedling development. Metabolomics. 2014; 10:958-974.

38. Ghatak A, Chaturvedi P, Nagler M, Roustan V, Lyon D, Bachmann G, Postl W, Schrofl A, Desai N, Varshney RK, Weckwert W. Comprehensive tissue-specific proteome analysis of drought stress responses in Pennisetum glaucum (L.) R. Br. (Pearl millet). Journal of Proteomics. 2016; Volume 143: 122-135.

39. Yu T, Li G, Dong S. et al. Proteomic analysis of maize grain development using ITRAQ reveals temporal programs of diverse metabolic processes. BMC Plant Biology. 2016; 16:241

40. Michaelson LV, Napier JA, Molino D and Faure JD.Plant sphingolipids: Their importance in cellular organization and adaption. Biochim Biophys Acta. 2016;1861(9Part B):1329-1335.

41. Coursol S, Fan LM, Le Stunff H, Spiegel S, Gilroy S, Assmann SM. Sphingolipid signalling in Arabidopsis guard cells involves heterotrimeric G proteins. Nature. 2003; 423:651-654.

42. Puli MR, Rajsheel P, Aswani V, Agurla S, Kuchitsu K, Raghavendra AS. Stomatal closure induced by phytosphingosine-1-phosphate and sphingosine-1-phosphate depends on nitric oxide and $\mathrm{pH}$ of guard cells in Pisum sativum. Planta. 2016; 244(4):831-41.

43. Okada M. Effects of Elevated CO2 on Floral Sterility of Rice Plants Caused by Low Temperature.Journal of Agricultural Meteorology.2005;60(5):589-592

44. Misra BB, Biswa RA, Granot D, Assmann SM and Chen S. The guard cell metabolome: functions in stomatal movement and global food security. Frontiers in Plant Science. 2005; 6:334

45. Wang X. Regulatory Functions of Phospholipase D and Phosphatidic Acid in Plant Growth, Development, and Stress Responses. Plant Physiology. 2005;139(2): 566-573.

46. Hong Y, Zhang W \& Wang X. Phospholipase D and phosphatidic acid signalling in plant response to drought and salinity. Plant, Cell and Environment. 2010; Vol 33:627-635.

47. Yamaoka Y, Yu Y, Mizoi J, Fujiki $Y$ et al. PHOSPHATIDYLSERINE SYNTHASE1 is required for microspore development in Arabidopsis thaliana. The Plant Journal. 2011; 67:648-661.

48. Bertomeu JM, Miñana BC, Segura Al, Mateu I, Nesi AN, Fernie AR, Segura J, Ros R. The Plastidial Glyceraldehyde-3-Phosphate Dehydrogenase Is Critical for Viable Pollen Development in 
Arabidopsis. Plant Physiology. 2010; Vol. 152: 80-1841.

49. Lalanne E, Honys D, Johnson A, Borner GHH, Lilley KS, Dupree P, Grossniklaus U, Twell D. SETH1 and SETH2, Two Components of the Glycosylphosphatidylinositol Anchor Biosynthetic Pathway, Are Required for Pollen Germination and Tube Growth in Arabidopsis. The Plant Cell. 2004; Vol. 16:229-240.

50. Ros R, Bertomeu JM, Krueger S. Serine in plants: biosynthesis, metabolism, and functions, Trends in Plant Science. 2004: Volume 19: Issue 9: P564-569.

51. Rubio S, Whitehead L, Larson TR, Graham IA and Rodriguez PL. The Coenzyme A Biosynthetic Enzyme Phosphopantetheine Adenylyl transferase plays a Crucial Role in Plant Growth, Salt/Osmotic Stress Resistance, and Seed Lipid Storage. Plant Physiology. 2008; Vol. 148:546-556.

52. Ahmad P, Rasool S, Gul A, Sheikh SA, Akram NA, Ashraf M, Kazi AM and Guce S. Jasmonates: Multifunctional Roles in Stress Tolerance Front. Plant Science. 2016; vol 7: article 813.

53. Geng S, Misra BB, Armas E, Huhman DV et al (2016) Jasmonatemediated stomatal closure under elevated $\mathrm{CO} 2$ revealed by timeresolved metabolomics. The Plant Journal. 2016; 88(6): 947-962.

54. Coursol S, Stunff HL, Lynch DV, Gilroy S, Assmann SM, Spiegel S Arabidopsis Sphingosine Kinase and the Effects of Phytosphingosine1-Phosphate on Stomatal Aperture. Plant Physiology. 2005; Vol. 137: 724-737.

55. Chen $L$ and Wang $L$. ALA Inhibits ABA-induced Stomatal Closure via Reducing $\mathrm{H}_{2} \mathrm{O}_{2}$ and $\mathrm{Ca}_{2}{ }^{+}$Levels in Guard Cells. Frontiers in Plant Science. 2016; volume 7: Article 482.

56. Sanders PM, Lee PY, Biesgen C, Boone JD, Beals TP, Weiler EW, Goldberg RB. The Arabidopsis DELAYED DEHISCENCE1 Gene Encodes an Enzyme in the Jasmonic Acid Synthesis Pathway. The Plant Cell. 2000; Vol. 12:1041-1061.

57. He Y, Fukushige H,Hildebrand DF and Gan S. Evidence Supporting a Role of Jasmonic Acid in Arabidopsis Leaf Senescence. Plant
Physiology. 2002; 128(3): 876-884

58. Saini S, Sharma I and Pati PK. Versatile roles of brassinosteroid in plants in the context of its homoeostasis, signalling and cross talks. Frontiers in Plant Science. 2005; 04:6: 950.

59. Jiang WB, Huang HY, Hu YW, Zhu SW. Brassinosteroid Regulates Seed Size and Shape in Arabidopsis. Plant physiology.2013;V ol.162:1965-1977.

60. Ye Q, Zhu W, Li L, Zhang S, Yin Y, Ma H and Wang X. Brassinosteroids control male fertility by regulating the expression of key genes involved in Arabidopsis anther and pollen development. PNAS. 2010; 107(13):6100-6105.

61. Kimple RJ, Kimple ME, Betts L, Sondek J \& Siderovski DP. Structural determinants for GoLoco ixcnduced inhibition of nucleotide release by Ga subunits. Nature. 2002; VOL416.

62. Siderovski DP and Willard FS. The GAPs, GEFs, and GDIs of heterotrimeric G-protein alpha subunits. International Journal of Biological Sciences.2005; 1:51-66.

63. Selva JP, Pessino SC, Meier MS, Echenique VC. Identification of Candidate Genes Related to Polyploidy and/or Apomixis in Eragrostis curvula. American Journal of Plant Sciences. 2012; 3:403-416.

64. Johnston CA, Willard MD, Kimple AJ, Siderovski DP \& Willard FS. A sweet cycle for Arabidopsis G-proteins. Plant Signaling \& Behavior. 2008; 3:12: 1067-1076.

65. Denis C, Aulière A, Galandrin S, Sénard JM and Galés C. Probing heterotrimeric $\mathrm{G}$ protein activation: applications to biased ligands. Current Pharmaceutical Design.2012; 18(2):128-144.

66. Zhao J and Wang X. Arabidopsis Phospholipase D_ 1 Interacts with the Heterotrimeric G-protein Subunit through a Motif Analogous to the DRY Motif in G-protein-coupled Receptors. The Journal of Biological Chemistry. 2004; Vol. 279(3): Issue of January 16:1794-1800.

67. Jones AM \& Assmann SM. Plants: the latest model system for G-protein research. EMBO Reports. 2004; Jun; 5(6):572-578. 


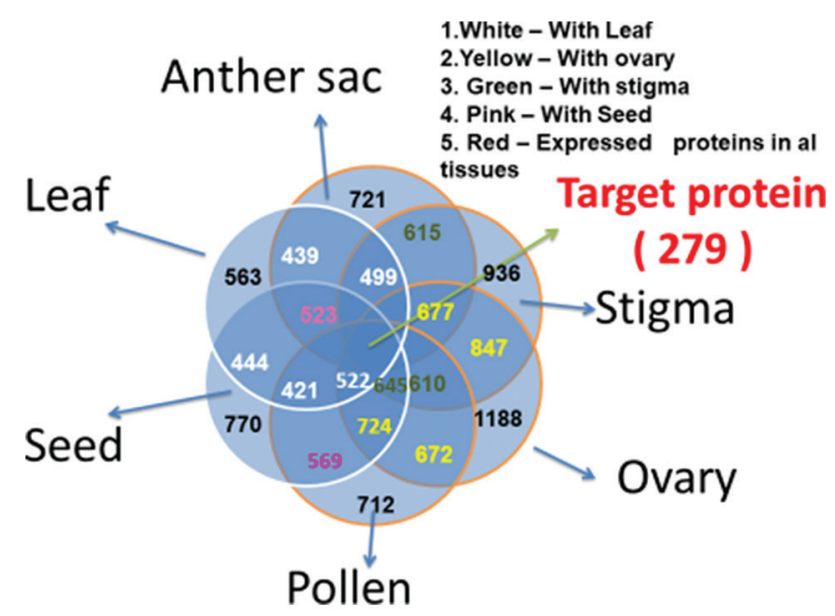

Figure S1: Target proteins of Cenchrus polystachion against rice database. The target proteins are commonly occurring proteins in all the tissues under study of Cenhrus polystachion. They contribute to the processes very prime to apomixis in this plant. Leaf is studied as a source and all other tissues act as sink. To establish source to sink relationship, these proteins are identified

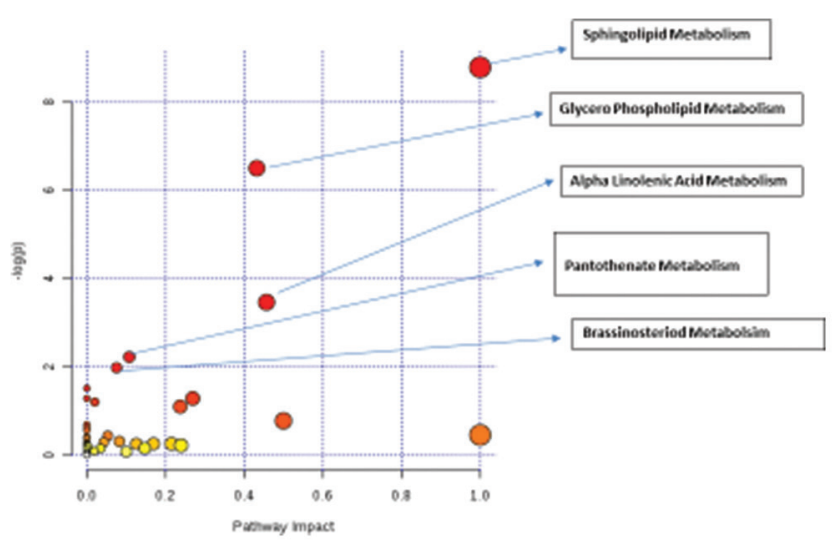

Figure S2: Pathway analysis of the statistically significant metabolites by Metaboanalyst 3.0. Each point represents one metabolic pathway; the size of dot is in positive correlation with the impaction of the metabolic pathway

Table S1: One-way ANOVA of metabolites

\begin{tabular}{|c|c|c|c|c|c|c|}
\hline P Value & $\mathrm{P}$ all & $P<0.05$ & $P<0.02$ & $P<0.01$ & $P<0.005$ & $P<0.001$ \\
\hline $\begin{array}{l}\text { Corrected } \\
\text { P value }\end{array}$ & 19296 & 3981 & 3971 & 3970 & 3970 & 3970 \\
\hline $\begin{array}{l}\text { Expected } \\
\text { by chance }\end{array}$ & & 199 & 79 & 39 & 19 & 3 \\
\hline
\end{tabular}

One-way ANOVA was performed using mass professional profiler B 2.00 (MPP) by agilent technologies, and out of 19296 metabolites 3981 metabolites gave $\mathrm{P}<0.05$. These were considered for PCA and pathway analysis 
Table S2: Metaboanalyst output for pathway analysis

\begin{tabular}{lccl}
\hline Pathway name & Match status & P value & Source \\
\hline Sphingolipid metabolism & $9 / 13$ & $6.6585 E-5$ & KEGG \\
Glycerophospholipid metabolism & $10 / 25$ & $6.1899 \mathrm{E}-5$ & KEGG \\
Pantothenate and CoA biosynthesis & $4 / 14$ & 0.050076 & KEGG \\
alpha-Linolenic acid metabolism & $5 / 23$ & 0.054827 & KEGG \\
Brassinosteroid biosynthesis & $3 / 25$ & 0.057804 & KEGG \\
\hline
\end{tabular}

Table S3: ImPaLa output for pathway analysis

\begin{tabular}{|c|c|c|c|c|}
\hline Pathway name & Overall metabolites & Total metabolites & $P$ value & Source \\
\hline Sphingosine 1-phosphate (SIP) pathway & 3 & $5(5)$ & $6.19 E-06$ & PID \\
\hline Phospholipid metabolism & 7 & $103(103)$ & $2.63 E-05$ & Reactome \\
\hline Glycerophospholipid biosynthesis & 6 & $94(94)$ & 0.000148 & Wikipathways \\
\hline Glycerophospholipid catabolism & 3 & $11(11)$ & $9.84 \mathrm{E}-05$ & Reactome \\
\hline Glycerophospholipid biosynthesis & 6 & $93(93)$ & 0.000139 & Reactome \\
\hline Sphingolipid metabolism & 5 & $67(67)$ & 0.000266 & Wikipathways \\
\hline Neurotransmitter release cycle & 4 & $37(37)$ & 0.000275 & Wikipathways \\
\hline Glycerophospholipid metabolism & 6 & $96(96)$ & 0.000166 & EHMN \\
\hline Phosphatidylinositol phosphate metabolism & 3 & $49(49)$ & 0.00871 & EHMN \\
\hline Vitamin B5 (pantothenate) metabolism & 2 & $17(17)$ & 0.00935 & Reactome \\
\hline Vitamin B5 - CoA biosynthesis from pantothenate & 2 & $21(21)$ & 0.0141 & EHMN \\
\hline Pantothenate and $\mathrm{Co} A$ Biosynthesis & 2 & $21(21)$ & 0.0141 & SMPDB \\
\hline Ceramide signaling pathway & 1 & $2(2)$ & 0.0174 & PID \\
\hline Phospholipid Biosynthesis & 2 & $24(24)$ & 0.0182 & SMPDB \\
\hline Linoleate metabolism & 2 & $24(24)$ & 0.0182 & EHMN \\
\hline
\end{tabular}

ImPaLa (Integrated Molecular Pathway Level Analysis) takes into account protein and metabolite data as input and gives all the relevant pathway associated with them with a measure of its $\mathrm{P}$ value. The list here includes only significant pathway details which have a $\mathrm{P}$ value $<0.05$ and which are complying with Metaboanalyst output. For more detailed output of ImPaLa see Supplementary file 